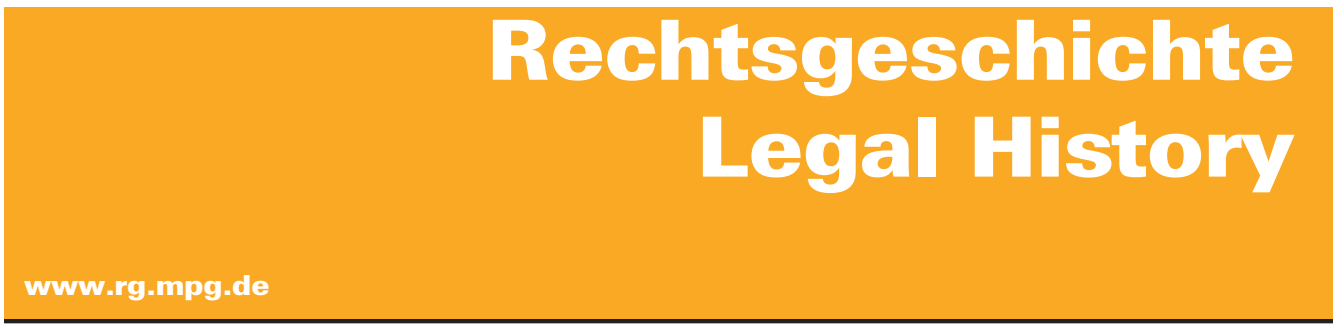

http://www.rg-rechtsgeschichte.de/rg23

$\operatorname{Rg} 232015 \quad 68-81$

Zitiervorschlag: Rechtsgeschichte - Legal History Rg 23 (2015)

http://dx.doi.org/10.12946/rg23/068-081

\title{
Miriam Czock
}

Zentralität in der Peripherie: Kirchengebäude als Orte des »Sonderfriedens« in den frühmittelalterlichen leges 


\section{Abstract}

In the early middle ages, specific protective rights were granted, among others, to church buildings. While legal historians investigating the legal protection of church buildings up till now stressed the jurisdictional concept of a »higher peace«, cultural history has drawn attention to the concepts of sanctuary and immunity. Drawing upon sources spanning from the Lex Salica to the capitularies and canon law of the $9^{\text {th }}$ century, the present article argues that peace, sanctuary and immunity are not to be understood as rooted in one concept, as is generally done, but rather they have to be understood as different legal concepts that only occasionally come together. Furthermore, I propose that the protection of church buildings is not an expression of taboo related to the sacral sphere of the king or the sacrality of the church building, but instead must be seen as rooted in a concept of honor that includes a spatial dimension and can be traced back to the motif of sfear of God «, but is ultimately guaranteed by law. The different concepts thus refer to the notion of churches not just as cult centres, but public protected areas, whose protection is part of a complex and comprehensive effort to restrict 'self-help'. From the perspective of the issue of centrality and periphery, the example clearly shows that this opposition is completely dissolved because places were created, instituted through legal protection, even at the periphery. 


\section{Miriam Czock}

\section{Zentralität in der Peripherie: Kirchengebäude als Orte des »Sonderfriedens" in den frühmittelalterlichen leges*}

Fragen nach Peripherie und Zentrum zielen nicht nur auf räumliche Dimensionen $\mathrm{ab}$, sondern richten sich gleichzeitig auf die damit verbundenen Rechtsverhältnisse. Wie sehr sich Raum und Recht miteinander verbinden, zeigt sich allein daran, dass die räumliche Radizierung von hoheitlicher Gewalt durch Recht bis heute als eines der Merkmale der Staatlichkeit gesellschaftlicher Gebilde gilt. ${ }^{1}$ Nun ist gerade für das Frühmittelalter, in dem die Gewaltausübung nicht auf eine Institution beschränkt war, nicht geklärt, wie Rechtsräume geschaffen wurden. ${ }^{2}$ Im Zusammenhang mit der Vorstellung von Zentralität einzelner Räume ist also zu analysieren, welche Räume rechtlich hervorgehoben und zu »öffentlichen« Einrichtungen erklärt wurden. Wenn man die Frage nach Zentrum und Peripherie nun an die frühmittelalterliche Rechtsetzung und damit an die rechtliche Hervorhebung einzelner Räume koppelt, wird es möglich, im Frühmittelalter kursierende Vorstellungen der Raum- und Rechtsordnung genauer zu beschreiben.
Die meisten der methodisch ganz unterschiedlichen Arbeiten, die sich bisher der Problematik von gesonderten Rechtsräumen im frühmittelalterlichen Recht gewidmet haben, bemühen sich letztlich darum, die Entwicklung des königlichen Gewaltmonopols darzustellen. ${ }^{3}$ Hierbei gilt die Befriedung einzelner Räume als die Wurzel eines in der Langzeitperspektive entstehenden, das gesamte Territorium durchdringenden Friedens. ${ }^{4}$ Dabei bewegt sich die Forschung zu den rechtlichen Vorstellungen von der Befriedung einzelner Räume im Frühmittelalter, wenn auch häufig nicht expliziert, immer noch in dem von Heinrich Brunner abgesteckten Rahmen, obwohl man seine Ansicht, dass es einen gemeinen Königsfrieden gab, der einem allgemeinen Königsschutz entsprach und sämtliche Untertanen des fränkischen Reiches umfasste, längst relativiert bzw. modifiziert hat. ${ }^{5}$ Seine These, dass es neben diesem allgemeinen Schutz durch den König verliehene Sonderschutzrechte gab, die einen höheren Sonderfrieden garantierten, ist hingegen kaum debattiert
* Für seine Bereitschaft zur Diskussion und für fruchtbare Hinweise zu diesem Aufsatz bin ich Lukas Bothe zu Dank verpflichtet. Außerdem möchte ich Alexander Berner und Melanie Panse für ihre Kommentare und Anregungen danken.

1 JellineK (1922) 394-406; WinkLER (1999), bes. 77-88; DreIER/

Wittreck (2009) 346-348; MaUrer (2010) 3 .

$2 \mathrm{Zu}$ den Raumvorstellungen im frühmittelalterlichen Recht siehe: EpP (1998). Zur Raumgliederung: EsDERS (2007).

3 Zum Frieden gibt es eine ganze Reihe von Arbeiten, die sehr unterschiedliche Aspekte von der Friedensidee bis hin zur Friedensumsetzung behandeln, hier nur eine Auswahl. Aus stärker rechtshistorischer Sicht: Dilcher (1996); Wadle (2006);
Hermann (2008). Zur frühmittelalterlichen Friedensidee siehe: Hartmann (1992).

4 Kampmann (2006) Sp. 6-8; Hermann (2008) Sp. 1814-1815.

5 Das Konzept, bestimmte Räume, Zeiten, Personen oder Personengruppen, zu denen auch die Kirche gehört, in einen königlich garantierten Frieden und damit in königlichen Schutz aufzunehmen, ist erstmals für die fränkische Zeit wohl in der Epistola Chlodovechi fassbar, siehe: Chlodowici regis ad episcopos epistola (507-511), in: Boretius (1883) 1-2: Quod ita ad integrum agnuscendum, ut ex his supradictis [das sind: sanctimunialibus, viduis, clericis vel filiis supradictorum, gemeint sind wohl die Waisen] si aliquis vim captivitatis pertulisset, sive in ecclesiis sive extra ecclesia, omnino sine aliqua dilatione reddendos esse praecipiamus. De caeteris quidem captivis laicis qui extra pace sunt captivati et fuerint adprobati, apostolis cui volueritis arbitrii vestri est non negandum. Nam de his qui in pace nostra tam clerici quam laici subrepti fuissent, si veraciter agnoscitis vestras epistulas de anulo infra signatas, sic ad nos omnimodis dirigantur et a parte nostra praeceptionem latam noveritis esse firmandam. Nach Heinrich Brunner ist der Brief der erste Beleg für die Einrichtung eines allgemeinen königlichen Friedens, siehe: BrunNer (1928) 50. Brunner stellt aber gleichzeitig fest, dass »in den fränkischen Quellen nicht von einer Munt, einem mundiburdium des Königs über alle Untertanen die Rede« sei (ebd. 62). Die Feststellung macht es schwer, den Schutz als aus einer rechtlichen Wurzel, d. h. der Munt, entspringen 
worden. ${ }^{6}$ Brunners Modell der Sonderschutzrechte bezieht sich in erster Linie auf Personengruppen oder einzelne Personen, aber auch auf Räume, die durch den König mittels Friedensverleihung hervorgehoben wurden. $\mathrm{Zu}$ diesen Friedensräumen gehören nach Brunner Kirchen und der Königsbzw. Herzogshof. Brunner denkt den Sonderfrieden dabei wie den Frieden allgemein systematisch vom König aus. So kam dem Königshof Frieden $\mathrm{zu}$, da der König sakrosankt war und seine Unantastbarkeit auf seine direkte räumliche und persönliche Umgebung übertragen wurde. Dazu bemerkt er für die Kirchengebäude: »Die Kirche erwirkte unter Ludwig I., daß die Kirchengebäude einen örtlichen Sonderfrieden nach Art des Pfalzfriedens erhielten. ${ }^{7}$ Zugleich stellt er fest, »dass die fränkischen Volksrechte von jenem örtlichen Königsfrieden schweigen. $\ll^{\mathbf{8}}$ Als Indizien für die Königsnähe und den somit geltenden höheren Frieden macht Brunner die für Vergehen in diesem Bereich fälligen höheren Bußen aus. ${ }^{9}$ Zwar ist das Gesamtkonzept Heinrich Brunners, das Kirchen und Königs- bzw. Herzogshof als Sonderfriedensräume auffasste, von der neueren Forschung rezipiert, jedoch kaum debattiert worden. ${ }^{10}$ Problematisch ist diese Tatsache, da Brunner einem positivistischen Rechtsbegriff folgt, der kaum mit den modernen Vorstellungen vom frühmittelalterlichen Rechtsbegriff vereinbar ist. ${ }^{\mathbf{1 1}}$ Es kann hier also nicht darum gehen, alle Prämissen des Brunner'schen Modells auf den Prüfstand zu stellen, sondern erst einmal nur darum, im Rahmen eines wichtigen Teilaspekts zu belastbaren Ergebnissen zu kommen. ${ }^{12}$ So soll die rechtliche Konzeption von Räumen im Frühmittelalter anhand des zentralen Ortes des Kirchengebäudes überprüft werden.

Wenngleich die stärker rechtshistorische Forschung das Interpretament der Sonderfrieden weitgehend unhinterfragt übernommen hat, hat die historisch-kulturwissenschaftliche Forschung einen neuen Ansatz verfolgt, ohne den systematisierenden rechtshistorischen Ansatz zu berücksichtigen. Sie hat sich vor allem mit Kirchen als Teil der königlichen Rechtssphäre auseinandergesetzt, allerdings auf anderen analytischen Ebenen, nämlich der des Asyls oder der Immunität. ${ }^{\mathbf{1 3}}$ Die Verschiebung der Forschungsperspektive ergab sich dabei teils aus der Entwicklung neuer Herrschaftsmodelle, die Königsherrschaft über die rein rechtlichen Faktoren hinaus als sozial-politisches Konstrukt betrachten, und teils aus der Verlagerung auf Urkunden und erzählende Quellen als Grundlage der Analysen. Mit Fokussierung auf die Urkunden treten Klöster bzw. das Kirchengut in den Blickpunkt, womit die Kirchengebäude nicht länger als selbständige Rechtssphären beleuchtet werden. ${ }^{\mathbf{1 4}}$ Die Akzentuierung der Immunitätsverleihung hat dazu geführt, dass die Schutzverleihung des Königs im Frankenreich für Kirchengebäude selber - und eben nicht ein Kloster oder das Kirchengut - nicht mehr als Etablierung eines eigenständigen Rechtsraums in das Modell eingeordnet wurde. ${ }^{15}$ Diese Perspektive bekommt darüber hinaus dadurch Ge- zu sehen, besser wäre es wohl, von rechtlichen Schutzinteressen zu sprechen. Ingrid Woll hingegen erkennt in dem Inhalt des Schreibens eine situative Regelung und den Frieden als zeitlich wie räumlich begrenztes Konzept, siehe: Woll (1995) 172. Zu Einordnungs- und den Interpretationsschwierigkeiten, die das Schreiben aufwirft, siehe ebd. 168-175. Eine umfassende Kritik findet sich bei: Goebel (1937) 1-61. Zum Problem des königlichen Friedens in der englischen Forschung siehe: LAMBERT (2009a) 164-171. Ich danke Thomas Lambert, dass er mir das Manuskript zur Verfügung gestellt hat.

6 Verena Epp hat in den leges 49 Fälle von besonders geschützten, da als öffentlich zu bezeichnende Räume, identifiziert. Sie spricht in Bezug auf diese von öffentlichem Eigentum, siehe: Epp (1998) 577, spezifischer zu den Kirchengebäuden als Rechtsraum: 581-583.

7 BrunNer (1928) Bd. 2, 69, ähnlich 61.

8 Brunner (1928) Bd. 2, 59.

9 BrunNer (1928) Bd. 2, 57-62, 69-70.

10 EpP (1998).

11 KANNOWSKI (2002); RÜCKERT (2006).

$12 \mathrm{Zu}$ den Möglichkeiten, den Bezug zwischen frühmittelalterlicher Staatlichkeit und Recht anders zu denken, siehe: EsDERs (2009) 423-432.

13 Das Asyl ist hier nur in Bezug auf das Kirchengebäude und zur Immunität von Belang, hier die Arbeiten, die sich mit Fragen in diesem Rahmen beschäftigen: Magnou-Nortier (1981), bes. 488; RosENWEIN (1999), bes. 109-112, 132-134, 227-228. Siehe außerdem zum Asyl allgemein:
ESDERS (1993); FRANKE (2003); Fruscione (2003). Zur Immunität: MurraY (1994); BrüHL (1995). David Bachrach sieht in der Immunität ein Werkzeug der Könige, die durch die Vergabe königlicher Ressourcen bzw. der Immunität politische Allianzen festigten, siehe: BACHRACH (2013), zur Forschungsdiskussion 1-7. Eine Studie zu England, die sich mit den Zusammenhängen zwischen Kirchenfrieden und königlichem Schutz auseinandersetzt und interessante Vergleichspunkte bietet, ist: LAMBERT (2009).

14 Semmler (1959); Heidrich (1973); Rosenwein (1999).

15 Das ist sogar schon in Brunners Modell der Fall, da auch er den Schutz aus den Urkunden der Karolinger ableitet: BRUNNER (1928) Bd. 2, 65-70. 
wicht, dass die Forschung davon ausgeht, die Immunität sei von den Karolingern mit dem Königsschutz verknüpft worden, wodurch eine neue Rechtsqualität entstand. ${ }^{\mathbf{1 6}}$ Als Referenztext gilt bezeichnenderweise das erste Kapitel aus den $\mathrm{Ca}$ pitula legibus addenda Ludwigs des Frommen von 818/9, die gleichzeitig als Konvergenzpunkt charakterisiert werden können: ${ }^{17}$ In ihm ist die Verbindung von Asylsuche, Immunität und rechtlichem Schutzinteresse im vollen Umfang und ausdifferenziert greifbar. ${ }^{\mathbf{1 8}}$ Die Rechtsmaterie kann aber von diesem späten Zeugnis aus nicht adäquat verstanden werden, vielmehr muss die schrittweise Verzahnung der Themenkreise in ihrem jeweils eigenen Denkrahmen beleuchtet werden; dies gelingt, zieht man als Quellen auch die leges und die auf sie verweisenden Kapitularien heran. Erst so erhellt, im Rahmen welcher Vorstellungen die Gesetzgeber versuchten, die Kirchen durch Rechtsverleihung an sich $\mathrm{zu}$ ziehen und $\mathrm{zu}$ zentralen Räumen zu machen. Gleichzeitig kann deutlicher werden, inwiefern Vorstellungen von Asyl, Immunität und rechtlichem Schutz des Kirchengebäudes korrelieren. Es kann hier nicht das Ziel sein, alle bisher zur Untersuchung herangezogenen Quellengruppen von den Urkunden bis zur Historiographie noch einmal zusammenzulesen, vielmehr soll den sich aus der bisherigen Forschung ergebenden Implikationen anhand der im Frankenreich entstandenen leges und der mit ihnen verbundenen Kapitularien nachgegangen und so neue Perspektiven entwickelt werden. Dabei geht es immer auch um das Verhältnis von Zentrum und Peripherie, entstehen doch viele der leges in den Randregionen des Reiches und reflektieren alleine deshalb den Versuch der institutionellen Formierung zentraler Räume.

Die Praxis, der Kirche Frieden zu gewähren, ist bereits unter Chlodwig nachweisbar. ${ }^{19}$ Die Aufnahme spezifisch der Kirchengebäude in die Rechtsordnung lässt sich hingegen zuerst aus einer Bestimmung der im 6. Jahrhundert entstandenen C-Rezension der Lex Salica ablesen, welche die Brandstiftung an Kirchengebäuden sanktioniert. ${ }^{20}$ In Paragraph 55,7 heißt es, dass derjenige, der eine Kirche anzündet, die entweder mit Reliquien bestückt worden ist oder eine Weihe erhalten hat, 200 solidi schulden soll. ${ }^{\mathbf{2 1}}$ Aus dem Text geht hervor, dass sich das Kirchengebäude durch die Reliquieneinbringung oder die Weihe definiert. Die Bedeutung des Vergehens schlägt sich in der relativen Höhe der Bußsumme von 200 solidi nieder. Die Sühne für einen Hausbrand beträgt hingegen gerade einmal $62 \frac{1 / 2}{2}$ solidi. $^{22}$ Daneben findet sich im vorletzten Paragraphen $(55,6)$ des Titels auch noch die Beraubung einer Basilika, die sich über einem Toten erhebt, als Vergehen, das mit 30 solidi Buße belegt ist. ${ }^{23}$ Auch hier wird eine Bußsumme erhoben, die doppelt so hoch ausfällt wie diejenige für die Beraubung anderer Grabmäler. Allerdings ist der Zusammenhang, in dem diese beiden Regelungen stehen, alles andere als eindeutig, finden sie sich doch nicht unter einem Titel, der sich mit Kirchengebäuden beschäftigt,
16 BrunNer (1928) Bd. 2, 69-71, 395-396; Kölzer (2005) 29.

17 Brunner (1928) Bd. 2, 61, 69-71, 395-395; RosenweIN (1999) 227-228.

18 Barbara Rosenwein widmet diesem Problem einen Exkurs, da die französische Forschung von der Idee ausgegangen ist, dass Asyl und Immunität in karolingischer Zeit nicht mehr unterschieden wurde. Sie lehnt diese Idee jedoch anhand des Kapitulars Ludwigs ab und plädiert für eine Eigenständigkeit der Immunität gegenüber dem Asyl, siehe: RosEnweIN (1999) 227-228.

19 S. Anm. 5.

20 Falls man Eckhardts Handschriftenklassifizierung folgt, enthält der 65Titeltext Chlodwigs keine Bestimmung zum Kirchengebäude, aller- dings bringen sie Handschriften C 5 und C 6. Die Handschriften C 5 und C 6 sind Teil der Recensio Guntchramna, welche 567-593 unter Gunthramn oder 593-596 unter Childebert II. entstand. Eine Übersicht bietet die Edition (1962) von Karl August Eckhardt: Pactus legis Salicae (Einleitung), S. XL. Zur Entstehung der Lex Salica siehe nun: UBL (2009); RENARD (2009).

21 Pactus Legis Salicae 55, 7 (ECKHARDT 1962, S. 209): Si quis basilicam, ubi reliquiae sunt inserta(e), aut ipsa basilica est sanctificata, incenderit, mallobergo chenechruda, solidos CC culpabilis indicetur.

22 Pactus Legis Salicae 16, 1 (ECKHARDT 1962, S. 71-73).

23 Pactus Legis Salicae 55, 6 (ECKHARdT 1962, S. 209): Si quis basilicam expo- liaverit desuper hominem mortuum, mallobergo chreotarsino, [MCC denarios qui faciunt] solidos $X X X$ culpabilis iudicetur [excepto capitale et d(i)latura]. 
sondern unter der Überschrift »Über die Grabmäler«. ${ }^{24}$ Ein nachdrückliches Interesse, Kirchengebäude als solche zu schützen, ist also nur tentativ anzunehmen. Zwar deutet die Höhe der Buße auf eine besondere Schwere der Tat hin, die Vergehen werden indes nicht mit einem Friedensgeld geahndet, das in der Lex Salica ohnehin erst in Ansätzen greifbar ist. In dieser Hinsicht ist die Lex Ribuaria ${ }^{25}$ aufschlussreicher; in ihr findet sich eine Bestimmung, die demjenigen, der der Kirche irgendetwas mit Gewalt entreißt, eine dreifache Buße der im vorangegangenen Gesetz angegebenen Summe auferlegt. ${ }^{26}$ Allerdings kann die Regelung nicht eindeutig auf die Kirche bezogen werden und muss, gerade was die räumliche Begrenzung der Geltung angeht, als unpräzise angesehen werden, da ecclesia nicht unbedingt das Kirchengebäude bezeichnen muss; der Begriff kann auch das Kirchengut benennen. ${ }^{27}$ Egal welcher Interpretation man eher zuneigt wird deutlich, dass nicht nur die kirchliche Organisation geschützt werden soll, sondern auch die besitzrechtlichen Interessen der Kirche. Gleichzeitig entwickelt die Lex Ribuaria die Anordnung in Parallele zu derjenigen zum vom König verbrieften und umgrenzten Land, denn mit der Wendung vorangegangenes Gesetz bezieht sich die Regelung zur ecclesia wohl auf den Einbruch in vom König verbrieftem und umgrenztem Land, der mit 60 solidi, also dem Königsbann, gebüßt werden soll. ${ }^{\mathbf{2 8}}$ Bemerkenswert ist, dass sich die Formulierung der Regelung zwar am Königsgut orientiert, der Kirche jedoch offenbar als unverletzbarem Raum einen höheren Wert beimisst, muss der Diebstahl doch mit dem Dreifachen seines Wertes gebüßt werden. ${ }^{29}$

Ist in der Lex Ribuaria nur dieser eine Ansatz dokumentiert, stellen sich die Dinge in den süddeutschen leges, die zu Beginn des 8. Jahrhunderts entstanden, komplexer dar. Die süddeutschen leges behandeln ein breiteres Themenspektrum als die
24 Herrmann Nehlsen plädiert dafür, dass in diesem Titel der Eingriff in die Bausubstanz bestraft werden soll, siehe: NeHLSEN (1978) 161. Dafür spricht auch die in der karolingischen Version der lex auftretende Trennung von Grabraub und Raub wie Brandstiftung an der Kirche in zwei einzelne Paragraphen, siehe: Pactus Legis Salicae, K 55, 6 (ЕскHARDT 1962,

S. 209): Si quis domum in modus balicae factum super hominem mortuum expoliauerit MCC denariis qui faciunt solidos XXX culpabilis iudicetur excepto capitale et delatura. Außerdem: Pactus Legis Salicae, K 58, 1 (EсKHARDT 1962, S. 209): Si quis ecclesiam sanctificatam uel ubi reliquiae sanctorum reconditae sunt incenderit uel infra ipsa ecclesia aliquam expoliationem de altare aut de infra ille ecclesia aliquid tullerit, VIIIM denariis qui faciunt solidos CC culpabilis iudicetur excepto capitale et delatura. Siehe hierzu auch: Czock (2012) 86-96, 198-200.

25 Die Forschung hat sich in den letzten Jahren kaum mehr der Lex Ribuaria zugewandt. So muss immer noch auf die grundlegenden Arbeiten zu Beginn des 20. Jh. verwiesen werden: BEYERLE (1928); BEYERLE (1935); BuCHNER (1952). Zu den Editionen und Entstehungs- sowie Datierungsfragen: ECKHARDT (1959); EwIG
(1976); Siems (1980), 97-98, 233-234.

26 Lex Ribuaria 58 c (BeYerLe/ BuchNER 1954, S. 107): Quod si quis de ecclesia aliquid vim tulerit, cum suprascribta lege in triplum conponat.

27 So die Interpretation der Editoren; siehe: Lex Ribuaria (Sachkommentar Zu 58 \C), (BEYerLe / BuCHNER 1954, S. 158). Übergriffe auf das Kirchengut werden in den leges und Kapitularien häufig unabhängig vom Kirchengebäude behandelt. Siehe z. B. Leges Baiwariorum 2-6 (v. ScHwind 1926, S. 270-276). Die Trennung deutet darauf hin, dass der Gesetzgeber sich der funktionalen Trennung von Kirchengebäude und -gut bewusst war. So sind auch die Vergehen unterschiedlich: Beim Schutz des Kirchengebäudes spielen die Aslyverletzung, der Mord in der Kirche und der Diebstahl aus der Kirche eine Rolle, bei den Regelungen, die das Kirchengut betreffen, geht es um die Entfremdung von Gütern und damit um die Schädigung der ökonomischen Grundlage. Siehe neben den entsprechenden Regelungen der Lex Baiuvariorum beispielsweise: Magnou-Notier (1992).

28 Lex Ribuaria 59, 1 (BeYerLe / BuchNER 1954, S. 106): Si autem infra testamentum regis aliquid invaserit, aut cum sex iuret, quod infra terminationem testamenti nibil invasisset, aut cum sexaginta solidos omnem repetitionem restituat. Für diese Zuweisung siehe: Lex Ribuaria (Sachkommentar zu $58 \$$ C), (Beyerle / Buchner 1954, S. 158). Zur Diskussion dieser Einschätzung, ohne letztliche inhaltliche Zurückweisung EcKHARdT (1959) 27-33. Eckhardts Edition weist die Regelung dem Titel $60 \mathrm{zu}$, womit aber der inhaltliche Zusammenhang meines Erachtens nach nicht zerrissen wird: ECKHARDT (1966) XL, 8, S. 64.

29 Lex Ribuaria (Sachkommentar zu 58 S C), Beyerle / Buchner 1954, S. 158. 
Lex Salica und die Lex Ribuaria. In ihnen eröffnet sich nun auch die Verfasstheit des den Herrscher umgebenden Raums genauer, da sich in ihnen Gebote zum Herzogshof finden. ${ }^{30}$ Bei der Ausformung des Kirchengebäudes als besondere Rechtssphäre erschließen sich vor allem im Asylrecht der Lex Alamannorum ${ }^{31}$ wichtige definitorische Abgrenzungen. Bereits in der ersten Regelung zum Asyl heißt es, dass egal ob ein Freier oder ein Unfreier (servus) dorthin geflohen ist, er weder mit Gewalt aus der Kirche entfernt noch getötet werden darf. Vielmehr soll der Verfolger aus Gottesfurcht und aufgrund der Ehre der Kirche die Kleriker bitten, den Verfolgten herauszugeben. Die Motivation der Anordnung wird auch in der zweiten Bestimmung aufgenommen, dort wird festgelegt, dass derjenige, der jemanden gewaltsam aus dem Asyl entfernte und damit der Kirche ein Unrecht zufüge, nicht nur die Kirche entschädigen, sondern auch 40 solidi an den Fiskus zahlen müsse, da er die Ehre (honor) der Kirche nicht geachtet habe. ${ }^{32}$ Die Ehre der Kirche tritt hier nun als eigene Kategorie der Charakterisierung des Vergehens auf; so verletzt der Asylbruch die
Ehre (honor) des Kirchengebäudes selbst und wird nicht nur aus Gottesfurcht verboten. ${ }^{33}$ Deutlich wird ein Bezug zwischen honor und der ecclesia als Raum hergestellt. Zudem wird der Raum des Vergehens dadurch näher definiert, dass er sich innerhalb der Kirchentüren befindet, womit eine deutliche Grenze zwischen Innen und Außen gezogen wird. ${ }^{34}$ Über die zugrunde liegenden Vorstellungen der sozialen bzw. ökonomischen Implikationen des Vergehens geben die Elemente der Buße Aufschluss. Der Asylbruch soll zum einen der Kirche als Geschädigte gebüßt werden, zum anderen wird er mit einem Friedensgeld geahndet, das an den Fiskus gehen soll. Es bildet sich also deutlich das Interesse ab, Vergehen in der Kirche als Vergehen auch gegen die Öffentlichkeit zu bestrafen. In Brunners Sinne formuliert: Es findet eine Ausdehnung des Königsfriedens auf die Kirchen statt.

Den Bestimmungen zum Asylrecht folgt in der Lex Alamannorum die Sanktion der Tötung innerhalb der Tore einer Kirche. ${ }^{35}$ Der Rechtssatz erklärt die Tötung als ein Unrecht gegen Gott und als Besudelung der Kirche Gottes. ${ }^{36}$ Wiederum kann
30 In rechtsorganisatorischer Hinsicht werden in den süddeutschen leges Bezüge zum Herzog anstatt zum König hergestellt. Festzustellen, inwiefern dazu die gesellschafts-politischen Entstehungsumstände beigetragen haben, liegt auf Grund der komplizierten Forschungslage außerhalb der Möglichkeiten und Zielsetzung der vorliegenden Studie. Zur Bedeutung des Herzogs in der Lex Alamannorum siehe: Schotт (1974) 148-149. Zur Abhängigkeit des Herzogs vom König in der Lex Baiuvariorum siehe: SiEms (2006) 48-53.

31 Es existieren mehrere Editionen der Lex Alamannorum. Die neueste ist von Clausdieter Schott (1997) anhand des Codex Sangallensi 731 vorgenommen worden. Das ausführlichste Verzeichnis von Sachparallelen findet sich in der ältesten Edition der lex durch Johannes Merkel (1863). Daneben sind noch eine Quartausgabe von KarL LeHMANN (1888) und eine verbesserte Fassung jener durch Karl August EckHardt (1966) vorgelegt worden, nach der an dieser Stelle zitiert wird. Zur Einschätzung der verschiedenen Editionen und der Überlieferungslage siehe: HARTMANN
(2004) 315-317, 313 Anm. 1, 319324. Die Lex Alamannorum als älteres Werk der beiden süddeutschen leges entstand in ihrer ursprünglichen Form wahrscheinlich unter der Herrschaft Chlothars II. in den Jahren 613-623. Erst die zweite Rezension, die ungefähr auf die Jahre von 712 bis $725 \mathrm{zu}$ datieren ist und heute allgemein als eine Kodifikation des alamannischen Herzogs Lantfried gilt, beginnt mit Kirchensachen. Die Datierung, die Zahl der Rezensionen wie auch der Schöpfer der lex sind umstritten. Zur älteren Forschung und grundlegend zur Lex Alamannorum siehe: SCHott (1974); HaRtmanN (2004). Clausdieter Schott hat in neuerer Zeit versucht, die lex als eine klösterliche Fälschung zu erweisen, siehe: Sснотт (2006).

32 Lex Alamannorum c. 3 (ЕскHARdT 1966, S. 69-70): Si autem vim abstraxerit et iniuriam ecclesiae fecerit, conponat 36 solidoas ad ecclesiam et fredo solvat in fisco 40 solidos, quare contra legem fecit et ecclesiae honorem non inpendit et Dei reverentiam non habuit, ut et alii congnuscant, quod sit timor Dei in christianis, et honorem ecclesiis inpendat.
33 Georges (1972). Zu Sakralität des Kirchenraums und der Verwendung des Begriffs honor in den süddeutschen leges siehe auch: Czock (2012) 134-143.

34 Semantisch ist der Begriff des honor bereits in der Antike unter anderem im Wortfeld der religiositas zu verorten, siehe: Georges (1972). Zum räumlichen Bezug des Begriffs siehe auch: Niermeyer (2002).

35 Lex Alamannorum 4 (ECKHARDT 1966, S. 70): Si quis liber liberum infra ianuas ecclesie occiderit, cognuscat se contra Deum iniuste ficisse et ecclesiam Dei polluit; ipsam ecclesiam, quod polluit, cum 40 solidis conponat, et fiscus fredum adquirat, parentibus autem legitimum wirigildum solvat.

36 Schon in der kanonikalen Gesetzgebung der merowingischen Zeit hatte sich ein Waffen- und Tötungsverbot in der Kirche angedeutet: Concilium Aurelianense A. 538, c. 32 (29), in: Clerce (1963) 125; Concilium Cabilonense A. 647-653, c. 17, Clerce (1963) 306-307. 
das Vergehen über die fälligen Bußen genauer kategorisiert werden: Hier müssen die Kirche mit 40 solidi, der Fiskus mit dem Friedensgeld, schließlich die Eltern des Getöteten mit dem Wergeld entschädigt werden. Während in der Lex Alamannorum der Asylbruch und die Tötung in der Kirche in besonderer Weise das öffentliche Interesse zu berühren scheint, spiegelt die Bestimmung zum Raub aus der Kirche dies nicht wider. Das erscheint folgerichtig, wenn man sich vor Augen führt, dass hier nicht der Diebstahl von Kirchengerät, sondern von Privateigentum aus der Kirche bestraft wird. ${ }^{37}$ Zwar finden sich in der Lex Baiuvariorum ${ }^{38}$ ähnliche Vergehen wie in der Lex Alamannorum, aber diese werden häufig in einen anderen Vorstellungsrahmen eingebettet. So wird die Unverletzbarkeit des Asyls in der Lex Baiuvariorum nicht mit dem Begriff des räumlichen honor verbunden, aber immerhin liegt der Anordnung die Ehrfurcht vor der heiligen Kirche als Prämisse zu Grunde. Sie legt fest, dass eine Buße erforderlich sei, damit Gottes Ehre und die Verehrung der Heiligen bestehen und die Kirche Gottes immer unverletzt bleibe. ${ }^{39}$ Wie in der Lex Alamannorum wird auch hier spezieller
Wert darauf gelegt, dass der Asylsuchende innerhalb der Türen der Kirche nicht verfolgt und auch nicht ausgeliefert werden darf. Für einen Verstoß gegen die Vorschrift wird eine Buße an die Kirche wie an den Fiskus fällig. Entfaltet die Lex Baiuvariorum das Asylrecht in einer der Lex Alamannorum recht ähnlichen Weise, wird das Thema des Diebstahls aus der Kirche in einer anderen Art diskutiert. Er wird einmal unter die Kirchensachen, d. h. die zum Beginn der lex verhandelten Rechte der Kirche, aufgenommen. Dort wird im Rahmen der Vergehen gegen das Kirchengut auch der Diebstahl des Kirchengeräts verhandelt, der eine Neungeldbuße nach sich zieht. ${ }^{40}$ Aufschlussreicher für die Profilierung der Kirche als besonderer Rechtsraum ist jedoch die Aufnahme des Diebstahls aus dem Kirchengebäude unter dem Titel »Vom Diebstahl ${ }^{41}$ Die betreffende Regelung besagt, dass wenn jemand etwas aus einer Kirche, im Hofe des Herzogs, in einer Schmiede oder in einer Mühle stiehlt, er es mit dem dreifachen Neungeld zu büßen hat, da jene vier Häuser öffentlich sind (publice sunt) und immer offen stehen. ${ }^{42}$ Entscheidend ist die Einreihung der Kirche unter die
37 Lex Alamannorum 5,1 (EcKHARDT 1966, S. 88): Si quis autem raptor res in ecclesia commendatas alicuis infra ianuas vim abstraxerit et tulerit, homine, cui fuerent, sicut lex habet, ita solvat; iniuriam autem eclesiae, quod raptum fecit, 36 solidos conponat.

38 Die Lex Bainvariorum wurde mehrfach ediert. Als die ausführlichste Edition gilt immer noch die von Johannes Merkel (1863), die einen detaillierten Sachapparat enthält. Daneben gibt es eine weitere Edition in der MGH durch ERnst von Schwind (1926), nach der im Weiteren zitiert wird. Zudem liegt die Handschrift B1 als Lichtbildabdruck mit Edition und Übersetzung von Konrad BeYerLE (1926) vor, dort findet sich auf S. XCII-XCIII auch eine Handschriftenübersicht. Eine neuere Handschriftenübersicht gibt: КоттJE (1986), siehe bes. die schematischen Abb. S. 19-21. Eine kurze, neuere Übersicht zum Forschungsstand bietet: Holzner (2010) 34-35. Die Entstehung der Lex Baiuvariorum ist das Thema einer langen Forschungsdiskussion, die vor allem um die Frage kreist, ob die lex ein einheitliches
Werk sei oder stufenweise entstanden ist. Auch heute ist die Diskussion darüber keineswegs beendet. Eine gute neuere Zusammenfassung des Forschungsstandes findet sich bei SiEms (2006) 31-37. Zur Einheitstheorie mit einem Entstehungsdatum um 740: LANDAU (2004) 3-12, 30-38; FASTRICH-SUTTY (2000) 17-39, 284-292; SchumanN (2006) 303-307, dort auch jeweils die ältere Forschungsliteratur. Zur Stufentheorie siehe auch: STÖrmer (1990) 157-160.

39 Lex Baiwariorum I 7 (v. SCHwIND 1926, S. 276-277): Si culpabilis aliquis confugium ad ecclesiam fecerit, nullus eum vi abstrahere ausus sit, postquam ianuam ecclesiae intraverit, donec interpellat presbyterum ecclesiae vel episcopum, si presbyter responsum dare ausus non fuerit; et si talis culpa est, ut dignus sit disciplina, cum consilio sacerdotis hoc faciat, quia ad ecclesiam confugium fecit. Nulla sit culpa tam gravis, ut vita non concedatur propter timorem Dei et reverentiam sanctorum, quia Dominus dixit: 'Qui dimiserit, dimittertur ei; qui non dimiserit, ne ei demittetur. Si quis autem homo contumax et superbus timorem Dei vel reverentiam ecclesiarum sanctarum non habuerit, et fugientem servum suum vel quem persecutus fuerit, de ecclesia vi abstraxerit et Deo honorem non dederit, conponat ad ipsum ecclesiam XL sold. iudice coegente et pro fredo ad fiscum XL sold, ut sit honor Deo et reverentia sanctorum et ecclesia Dei semper invicta sit.

40 Lex Baiwariorum I 3 (v. Schwind 1926, S. 270-272): Si quis res ecclesiae furaverit et exinde probatus fuerit, unaquam rem niungeldo solvat, id est novem capita restituat. Et si negare voluerit, secudum qualitatem pecuniae iuret in altare de qua ecclesia furaverit. (...) Si autem de ministerio ecclesię aliquid furaverit, id est calicem aut patenam vel pallam, aut qualcumque rem de infra ecclesia furaverit et probatus fuerit, triniungeldo solvat, hoc est ter novem restituat. (...)

41 Lex Baiwariorum IX (v. ScHwIND 1926, S. 366).

42 Lex Baiwariorum IX 2 (v. Schwind 1926, S. 367-369): Et si in ecclesia vel infra curte ducis vel in fabrica vel in mulino aliquid furaverit, triunungeldo conponat, hoc est ter novem reddat, quia iste IIII domus casae publicae sunt et semper patentes. (...) 
anderen öffentlichen Orte im Zusammenhang mit dem Diebstahl. Hier spielt auf keiner Ebene die Idee der Sakralität eine Rolle, vielmehr kommt zum Ausdruck, dass die Kirche wie andere Orte auch ein öffentlicher - ja sogar offener - Raum ist, dessen Inhalt deshalb vor Übergriffen geschützt werden soll. Dabei ging es wohl nicht zuletzt um die Aufrechterhaltung wichtiger Infrastruktur, wobei ferner das einer Gemeinschaftsnutzung innewohnende größere Konfliktpotential antizipiert wird. Der Rechtssatz reflektiert, dass im Falle des Diebstahls die Kirche nicht von anderen öffentlichen Orten differenziert wird. Gleichsam betont der Rechtssatz damit eine gesteigerte Bedeutung der Kirche als unverletzlicher Raum. Im Gegensatz zur Lex Salica und Lex Ribuaria enthalten die süddeutschen leges konkrete Hinweise darauf, dass die Kirchengebäude Orte waren, die als Schutzräume konzipiert waren. Dahinter scheint ein öffentliches Interesse gestanden zu haben, konfliktfreie Zonen einzurichten. Insofern hat Brunner Recht, wenn er davon ausgeht, dass es in der frühmittelalterlichen Rechtsordnung hervorgehobene Orte gab. Es scheint aber eine zu einfache Gleichung zu sein, den Kirchenfrieden auf den Pfalzfrieden zurückzuführen ${ }^{\mathbf{4 3}}$ und die einzelnen Räume zu stark in einen durchgehenden rechtssystematischen Zusammenhang zu bringen. Hier lohnt sich ein kurzer vergleichender Blick auf die Bestimmungen für weltliche Räume. In den beiden süddeutschen leges wird es verboten, am Herzogshof einen Kampf oder Streit zu entfachen, eine Zuwiderhandlung wird unter anderem mit einem Bußgeld an den Fiskus geahndet. ${ }^{44}$ Auch der Diebstahl aus dem Herzogshof wird verboten. ${ }^{45}$ In der
Lex Alamannorum wird darüber hinaus für die Tötung eines Menschen auf dem Hin- und Rückweg zum sowie im Hof des Herzogs eine Buße erhoben. Das Vergehen muss mit einem dreifachen Wergeld gebüßt werden, da das Gebot des Herzogs übertreten wurde und der Frieden (pacem) nicht gewahrt wurde. ${ }^{46}$ Der Hin- und Rückweg wird zusätzlich durch das Verbot jedweder Störung gesichert. ${ }^{47}$ Damit ist auch der Herzogshof ein Ort, an dem Konflikte keinen Platz haben sollen, und in der Lex Alamannorum wird er sogar explizit mit dem Frieden verbunden. Den Vorschriften liegt dennoch teils ein anderer Denkrahmen zugrunde als denjenigen für das Kirchengebäude, da sie alleine als präventive Maßnahmen wirken sollen, um Konflikte zu verhindern. Hingegen hat die Asylgewährung im Kirchengebäude eine besondere Gewichtung. So sollen sie im Konfliktfall Rückzugsräume darstellen, um der immer möglichen gewaltsamen Eskalation von Auseinandersetzungen einen Riegel vorzuschieben. ${ }^{\mathbf{4 8}}$ Darüber hinaus spielen die für den Kirchenschutz in Anschlag gebrachten Argumente, wie die Ehrfurcht vor Gott oder den Heiligen, keine Rolle. Kann man dies noch als eine Selbstverständlichkeit werten, fällt jedoch auch auf, dass dem Herzoghof selber keine besondere räumliche Qualität wie die eines honor zugeschrieben wird, sondern hier der Akzent auf den Frieden gelegt wird, den die Personen haben sollen.

Gedanken zur Sonderstellung der Kirchengebäude finden sich auch in den in karolingischer Zeit entstandenen Gesetzeskodifikationen, die jedoch einige Erweiterungen und Differenzierungen enthalten. Besonders bezeichnend ist es, dass die
43 So auch Goebel (1937) 12. Allerdings geht er davon aus, dass es sich hierbei um eine Gesetzgebung zugunsten der Götter handelt. Den leges ist jedoch ein viel breiteres Motivationsspektrum zu entnehmen.

44 Lex Alamannorum 33 (ECKHARDT 1966, S. 90-91): Si quis in curte duci pugna comiserit, et ibi clamor orta fuerit, et concursio populi facta fuerit per eius commissum, quidquid ibi factum fuerit per concursum eius, qualiscumque homo neglexerit et aliquid contra legem fecerit, tripliciter conponat. Ille autem, per cuius voce vel opere haec contentio orta fuerit, 60 solidos in publico conponat. Vgl. auch Lex Baiwariorum II 10-11 (v. Schwind 1926, S. 304-305).
45 Lex Alamannorum 31, 1 (ECKHARDT 1966, S. 89-90): Si quis in curte regis furtum alicui fecerit, dupliciter conponat, cui furtum fecerit, et 60 solidos pro fredo in publico solvat. (...). Vgl. auch Lex Baiwariorum II 12 (v. Schwind 1926, S. 306).

46 Lex Alamannorum 28, 1 (ECKHARDT 1966, S. 87): De his, quis in curte duci hominem occiderit aut ibi ambulantem aut inde revertentem, triplice wirigildum eum solvat, pro boc quod praeceptum duci transgressus est, ut unusquisque homo pacem habeat ad dominum suum veniendo et de illum revertendo.

47 Lex Alamannorum c. 28, 2 (EcKHARDt 1966, S. 88): Ut nullus praesumat hominem de duci venientem aut ad illum ambulantem in itinere inquietare, sivis culpabilis sit; et si praesumpserit, quidquid ei fecerit aut occiderit, aut ille vivens evaserit et placatus fuerit, semper tripliciter eum conponat.

$48 \mathrm{Zu}$ diesem Aspekt siehe auch: Fruscione (2003) 85-89, 189-192. 
bereits entfalteten Rechtsnormen in die Gesetzgebung für die neueroberten Gebiete Sachsens integriert wurden, indem unter anderem die Capitulatio de partibus Saxoniae den bisher erarbeiteten Kanon der Vergehen aufnimmt. ${ }^{49}$ Damit wird besonders deutlich, dass der Versuch gemacht wurde, in peripheren Regionen des Reiches Kirchen durch Recht zu Zentren zu machen. Bereits der erste Titel der Capitulatio bezieht sich auf die Kirchengebäude: Er legt fest, dass den Kirchen, die gerade in Sachsen gebaut werden und die Gott geweiht sind, nicht weniger, sondern größere und hervorragendere Ehre (honor) zuteil werden solle, als sie die Tempel der Götzen gehabt haben. ${ }^{50}$ Die Capitulatio formuliert so eine programmatische Begründung zur Bedeutung der Kirchen in der Gesellschaft mit dem Rückgriff auf das Konzept des honor, das schon in der Lex Alamannorum Verwendung fand. Die zweite Bestimmung setzt sich mit dem Asyl auseinander und bezeichnet die Kirchen eigens als verehrungswürdige Orte. So wird erneut bestimmt, dass niemand berechtigt ist, einen Asylsuchenden gegen die Ehre Gottes und der Heiligen und die Verehrung, die den Kirchen selbst zusteht, mit Gewalt aus dem Asyl zu holen, sondern dass der Asylant dort Frieden haben soll. ${ }^{51}$ Die zweite Bestimmung der Capitulatio ist damit eine der wenigen Bestimmungen, in denen sich der Begriff des Friedens im Begründungszusammenhang der auf das Kirchengebäude bezugnehmenden Regelungen explizit wiederfindet. Daneben werden die Brandstiftung am Kirchengebäude, der Raub aus der Kirche sowie das gewaltsame Eindringen in die Kirche mit der Todesstrafe sanktioniert. ${ }^{52}$ Was der Capitulatio zur Konzeption des Raumes zu entnehmen ist, orientiert sich zwar an dem bisher erarbeiteten Normenbestand, weicht allerdings mit der Forderung der Todesstrafe vom typisch fränkischen Kompositionssystem ab. Das ist ein charakteristisches Merkmal der Gesetzgebung in Sachsen und wird zumeist als ein Ausdruck einer aufgrund der Eroberung notwendigen nachdrücklichen Durchsetzung der Normen angesehen. ${ }^{53}$ Die Lex Saxonum gleicht in dieser Hinsicht der Capitulatio, erweitert aber noch einmal die Tatbestände; so droht auch sie demjenigen mit dem Tode, der jemanden in der Kirche ermordet, etwas aus ihr raubt, sie aufbricht oder dort wissentlich einen Meineid schwört. ${ }^{54}$ Die Lex Saxonum enthält damit den umfassendsten Vergehenskatalog: neben den Mord und den Diebstahl tritt der Meineid, der in der leges-Gesetzgebung zum Kirchengebäude sonst nicht erscheint. ${ }^{55}$ Das Verbot eines Meineides in der Kirche war allerdings im Rahmen der Gesetzgebung der Kapitularien erfolgt; so verbietet ihn beispielsweise die Admonitio generalis. ${ }^{56}$ Auch in anderer Hinsicht wird der Normenschatz in der Lex Saxonum bedeutend erweitert, dehnt sie den
49 Zur Capitulatio, die üblicherweise um 797 datiert wird, siehe: SCHUBERT (1993) 3-28. Zur Einordnung der Gesetzgebung zu Sachsen siehe: SPringer (2009) bes. 292-301, dort auch 295 zu den Datierungsschwierigkeiten der Capitulatio. Einen Vorschlag der Datierung um 795 machte HeN (2006) $48 \mathrm{f}$.

50 26. Capitulatio de partibus Saxoniae $775-790$ c. 1 , in: Boretius (1883) 68 Constitute sunt primum de maioribus capitulis. Hoc placuit omnibus, ut ecclesiae Christi que pro modo construuntur in Saxonia et deo sacratae sunt, non minorem habeant honorem sed maiorem et excellentiorem quam vana [sic!] habuissent idolorum.

51 Ebd., c. 2, S. 68: Si quis confugiam fecerit in ecclesiam, nullus eum de ecclesia per violentiam expellere presumat sed pacem habet usque dum ad placitum praesentetur et propter honorem Dei sanctorumque ecclesiae ipsius reveren- tiam concedatur ei vita et omnia membra (...)

52 Ebd., c. 3, S. 68: Si quis ecclesiam per violentiam intraverit et in ea per vim vel furtu aliquid abstulerit vel ipsam ecclesiam igne cremaverit, morte moriatur. Zur Einordnung der Todesstrafe siehe: NeHLSEN (2008).

53 Zusammenfassend: Becher (2013) bes. 325-326. Siehe auch: Schubert (1993) bes. 3; Hen (2006). Siehe für eine abwägendere Sicht: NeHLSEN (2008).

54 Lex Saxonum XXI (v. Schwerin 1918 S. 24): Qui in ecclesia hominem occiderit vel aliquid furaverit vel eam effregerit vel sciens periuraverit capite puniatur.

55 Lex Frisionum X 1 (EcKHardT / EcKHARDT 1982 S. 52) belegt den Meineid auf die Reliquien mit einer Buße.

56 Admonitio generalis, c. 63 (MordeK u. a. 2012, S. 214): Omnibus: Item habemus in lege domino praecipiente:
Non periurabis in nomine meo nec pollues nomen domini dei tui. Et: $\mathrm{Nec}$ adsumes nomen domini dei tui in vanum. Ideo omnino ammonendi sunt omnes diligenter, ut caveant periurium non solum in sancto evangelio vel in altare seu in sanctorum reliquiis, (...). Item ipse dominus in euangelio: Ego sum via et veritas. Ideo, qui in veritate et caritate iurat, in deo iurat. Item cavendum est, ne farisaica superstitione aliquis plus aurum honoret quam altare, ne dicat ei Dominus: Stulte et caece, quid est maius: aurum vel altare quod sanctificat aurum? Sed et nobis honestum videtur, ut, qui in sanctis habeat iurare, hoc ieiunus faciat cum omni bonestate et timore dei et sciat, se rationem redditurum deo uniuscuiusque iuramenti ubicumque sit, sive intra ecclesiam, sive extra ecclesiam. 
Schutz doch auf den Hin- und Rückweg zur Kirche an den Festtagen aus, an denen die Kirche anscheinend besucht werden soll. Demjenigen, der dem Tötungsverbot zuwiderhandelt, wird die Todesstrafe auferlegt; wer einen Hinterhalt legt, erhält hingegen nur eine Bußstrafe. ${ }^{57}$ Hier ließen sich strukturell wohl am ehesten Verbindungslinien zu dem in der Lex Alamannorum mit dem Herzogshof verknüpften Frieden ziehen. Das Beispiel aus der Lex Saxonum zeigt in einiger Deutlichkeit, dass räumliche bzw. zeitliche Strukturen geschaffen werden sollten, welche die religiös geforderte Teilnahme am Kult in Zeiten gewaltsamer Auseinandersetzungen sichern sollten. Hier findet sich also schon früh ein Gedanke, der von der Forschung traditionell eher mit den Gottesfrieden in Zusammenhang gebracht wird, nämlich die Idee, bestimmte Zeiten und Orte, die vor allem mit der Ausübung des Kultes zusammenhängen, vor Gewalt zu schützen. ${ }^{58}$ In ähnlichen Bahnen bewegt sich die Lex Frisionum, denn sie legt fest, dass wer einen Mann am Hofe des Herzogs, in der Kirche oder im Atrium der Kirche tötet, neunfach dessen Wergeld zu büßen habe und gleichfalls das neunfache Friedensgeld dem Herrn schulde. ${ }^{59}$ Wie in der Lex Baiuvariorum stehen hier weltlicher und »heiliger« Schutzraum ganz unterschiedslos nebeneinander, auch wenn der Vergehenszusammenhang nicht Diebstahl, sondern Mord ist. In einer weiteren Bestimmung wird die von der Lex Frisionum angesetzte Analogie weitergeführt: Sie besagt, dass ein Befehdeter in der Kirche, auf dem Hin- und Rückweg, in seinem Haus und auf dem Weg zum Gericht Frieden haben soll. ${ }^{\mathbf{6}}$ Der Regelung liegt der Gedanke zugrunde, dass die Selbsthilfe - wie sie in der Fehde zum Ausdruck kommt - an bestimmten Orten ausgesetzt werden muss. Die lex geht dabei über die Lex Saxonum hinaus, denn hier soll nicht nur die Einhaltung der christlichen Pflichten geschützt werden, sondern ebenfalls der alltägliche Lebensvollzug wie die Möglichkeit, am Gericht teilzunehmen. Dadurch kann das Verbot als Versuch interpretiert werden, die Strukturen der öffentlichen Zwangsgewalt zu stärken, denn indem der Weg zum Gericht gesichert wird, kann das Gericht als alternative Rechtsinstanz zur Fehde gestärkt werden. In den leges tritt ein komplexes Vorstellungsgeflecht hervor, das das Kirchengebäude als einen ausgesonderten und verbürgten Friedensraum erscheinen lässt, der sich
57 Lex Saxonum XXIII (v. ScHwERIN 1918 S. 24): Qui homini ad ecclesiam vel de ecclesia die festo pergenti, id est dominica, pascha, pentecosten, natale Domini, sanctae Mariae, sancti Iohannis baptistae, sancti Petri et sancti Martini, insidias posuerit eumque occiderit, capite puniatur; si non occiderit, tamen insidias fecerit, bannum solvat de reliquis.

58 Eine Untersuchung denkbarer Anknüpfungspunkte an die älteren Rechtsvorstellungen sowie möglicher Ähnlichkeiten der Gottesfrieden mit der älteren Gesetzgebung wäre lohnenswert. So hat vor längerer Zeit Hartmut Hoffman in seiner Studie zu den Gottesfrieden festgestellt: »Daher bleibt es fraglich, ob die Treuga Dei bei ihrer Entstehung einen dünnen Faden weiterspann, der seit der karolingischen Epoche nicht abgerissen war.« Siehe: HoffmanN (1964) 71. Auf der Ebene der Entfremdung des Kirchengutes sieht Elisabeth Magnou-Nortier (1992) Bezüge zu den älteren Bestimmungen zum Gottesfrieden. Zu der Forschung über die Gottesfrieden siehe: WADLE (1996); Head/Landes (1992); Goetz
(2002); GERGEN (2004). Goetz' These, dass die Gottesfrieden die Selbsthilfe eindämmen und nicht die Fehde grundsätzlich bekämpfen sollten (ebd. 41), lässt sich auf den Umgang der leges mit der Selbsthilfe übertragen. Vielleicht ließe sich auch ein »dünner Faden« zu einem Kapitular Karls des Kahlen ziehen, in dem das Zusammenspiel von Kirche und weltlichen Großen wie deren Strafmitteln, in Bezug auf den Immunitätsbruch festgeschrieben wird: Caroli (Calvi?) Capitulum de immunitate infracta, in: Mordek (1995) 1020, ITEM DE IMMUNITATE INFRACTA (INFRA 1). KAROLUS AUGUSTUS Si quis infra claustra ecclesiarum dei violenter intraverit et immunitatem infringere presumserit, usque ad satisfactionis eqmendationem veniat, omnium communione privetur et sanctę dei ęclesię liminibus arceatur; nec cum fidelibus communicet, qui sacrosancto loco divino cultui consecrato vim inferre non metuit. Primum ergo ab episcopis innotescendum, ut nullius communioni iugatur, donec emendando satisfaciat. Commes vero pagi ipsius eum per bannum venire faciat, et per legem omnia emendare compellatur et pro dampno, quod in immunitate fecit DC solidos componat. Si autem ipse nec episcopis nec commiti adquieverit, a missis nostris compraehensus in causas nostra legales (...) deducatur et pro eo quod episcopis inobediens fuit et commitis nostri et scabinorum iudicio non adquievit et bannum nosterum transgessus est, per legem iudicatus capitali sententia puniatur, et res ipsius in fiscum nostrum redigantur.

59 Lex Frisionum XVII 2 (ECKHARDT / ECKHARDT 1982 S. 62): Qui in curte ducis, in ecclesia aut in atrio ecclesiae hominem occiderit, novies weregildum eius componat, et novies fredam ad partem dominicam.

60 Lex Frisionum, Additio sapientum, Welmarus I,1 (ECKHARDT / ECKHARDT 1982 S. 80): Homo faisosdus pacem ha beat in ecclesia, in domo sua, ad ecclesiam redeundo, ad placitum eundo, de placito redeundo. Qui hanc pacem effregerit et hominem occiderit, novies XXX solid(os) com(ponat). 
teils parallel $\mathrm{zu}$ anderen weltlichen Friedensorten entwickelt, aber gerade in der Frage des Asyls von diesen abgekoppelt bleibt. Hier kann sich nun auch die Frage nach dem Zusammenhang von Immunität, Asyl und rechtlichem Schutz anschließen. Unter den Karolingern fand nicht nur die Emendation der Lex Salica sowie die Sammlung der Lex Saxonum, der Lex Frisionum und der Lex Thuringorum statt, vielmehr erließen die Könige ebenfalls einige Kapitularien, die anscheinend der Überarbeitung der leges dienten. Betrachtet man diese, stellt man strukturelle Ähnlichkeiten zum bisher besprochenen fest, auch wenn sie sich auf die Immunität beziehen. Im Jahr 803 erließ Karl der Große nämlich ein Kapitular, ${ }^{61}$ in dem bestimmt wird, dass wer auch immer in einer Immunität einen Schaden anrichtet 60 solidi zahlen soll. ${ }^{62}$ Im gleichen Kapitel wird außerdem geregelt, dass wer in eine Immunität flieht, dort nicht dem Gericht entgehen kann, sondern dem Grafen zur Rechtsprechung übergeben werden soll. Schon Barbara Rosenwein hat mit Blick auf diese Vorstellungen darauf aufmerksam gemacht, dass die Immunität nicht mit dem Asyl gleichgesetzt werden darf, da das Asyl in der Kirche im selben Kapitular im Gegensatz zur Immunität als absolut unverletzlich gilt. ${ }^{63}$ In der Normsetzung unter Karl dem Großen spiegelt sich so ein Unterschied zwischen der Immunität und der Kirche, der auch unter seinem Sohn Ludwig dem Frommen erhalten bleiben sollte und dessen Regelung anscheinend mit dem Zuwachs der Immunitätsverleihungen unter den Karolingern zusammenhängt. Unter Ludwigs Herrschaft entstand 818/819 ein weiteres Kapitular als Zusatz zu den leges, das ebenfalls auf den Zusammenhang zwischen Immunität und Kirchengebäude eingehen sollte. Keine der frühen weltlichen wie kirchlichen Regelungen enthält auch nur annähernd so detaillierte Angaben wie das Kapitular Ludwigs, das insgesamt durch Differenzierung zu einer möglichst umfassenden Rechtsordnung kommt. ${ }^{64}$ Die Bestimmung zum Totschlag in der Kirche ist mit »Über die Ehre der Kirchen« überschrieben. Der Titel nimmt so den bereits in der Lex Alamannorum verwendeten Begriff des honor wieder auf und macht ihn zum übergreifenden Konzept. Inhaltlich geht es um den Totschlag in der Kirche. So legt das Kapitular fest, dass wenn jemand einen anderen ohne Grund in der Kirche erschlägt, er mit dem Tod bestraft werden soll; wenn derjenige jedoch aus Selbstverteidigung gehandelt hat, muss er der Kirche mit 600 solidi und dem königlichen Bann büßen. Bei der Bemessung der Strafe oder Buße geht es also nicht einfach nur um den Raum, der geschützt werden soll, sondern ebenso um die Umstände, unter denen eine Tötung geschah. Entsprechend nuanciert ist das Nachdenken über den Raum in diesem Kapitular zu fassen, denn auch von ihm hängt die Buße ab. Zum einen wird der Vorhof einer Kirche, dessen Tor mit Reliquien von Heiligen geweiht wurde, mit dem Kircheninneren gleichgesetzt. ${ }^{65}$ Zum anderen sieht die Bestimmung als denkbar an, dass das Tor des Atriums nicht durch Reliquien geheiligt wurde. In diesem Falle sollte der Täter nur büßen, als ob er das Vergehen in der Immunität begangen hätte. ${ }^{\mathbf{6 6}}$ Hier entfaltet sich nun eine genaue Abstufung der Räume, welche das erste Mal die Immunität mit einbezieht. Deutlich bestehen bleibt jedoch
61 Zur Einordnung des Kapitulars in die leges Reform siehe: Patzold (2005).

62 Capitulare legibus additum (803), c. 2, in: Boretrus (1883) 113: Si quis in emunitatem damnum aliquid fecerit, DC solidos componat. Si autem homo furtum aut homicidium vel quodlibet crimen foris committens infra emunitatem fugerit, mandet comes vel episcopo vel abbati vel vicedomino vel quicumque locum episcopi vel abbatis tenuerit, ut reddat ei reum.

63 Ebd., S. 113: Si quis ad ecclesiam confugium fecerit, in atrio ipsius ecclesiae pacem habeat, nec sit ei neccesse ecclesia ingredi, et nullus cum inde per vim abstrabere praesumat; sed liceat ei confiteri quod fecit et inde per manus bo- norum hominum ad discussionem in public perducatur. Siehe hierzu auch: Rosenwein (1999) 228.

64 Patzold (2005).

65 Capitula legibus addenda (818/9), c. 1 , in: Boretius (1883) 281: De honore ecclesiarum: Si quis aut ex levi causa aut sine causa hominem in ecclesia interfecerit, de vita conponat. Si vero foris rixati fuerint, et unus alterum in ecclesiam fugerit et ibi se defendendo eum interfecerit, si huius facti testes non habuerit, cum duodecim coniuratoribus legitimis per sacramentum adfirmet se defendendo eum interfecisse, et post haec sexcentos solidos ad partem ecclesiae quam illo homicidio polluerat et insuper bannum nostrum solvere cogatur; is vero qui interfectus est absque conpositione iaceat: ac deinde interfector secundum iudicium canonicum congruam facinori quod admisit paenitentiam accipiat. (...) Si in atrio ecclesiae, cuius porta reliquiis sanctorum consecrata est, buiuscemodi homicidium perpetratum fuerit, simili modo emendetur vel conponatur; si vero porta ecclesiae non est consecrata, eo modo conponatur quod in atrio conmittitur; sicut conponi debet quod in inmunitate violata conmittitur.

66 Zur Frage der Immunität siehe: RosenWEIN (1999) 228. 
eine Unterscheidung zwischen der Immunität und den geheiligten Räumen. Dass erst jetzt dahingehend differenziert wird, dass die Immunität einbezogen wird, ist nicht verwunderlich, kommt es doch erst in der Zeit Ludwigs des Frommen zu einer breiteren Vergabe der Immunität auch an Kirchen. ${ }^{67}$

Zwar kann nicht geleugnet werden, dass die Immunität einen starken räumlichen Aspekt hat, da sie einen Raum darstellt, der vor dem Eingriff anderer Richter als des Königs schützt, sie umschließt aber anders als in den bisher besprochenen Quellen hier nicht nur den engeren Kirchenraum, sondern den gesamten Kirchenbesitz und bezieht sich in erster Linie auf diesen. ${ }^{68}$ Die Unterscheidung zwischen Immunität und Kirchen als konfliktfreie Räume findet so auch Niederschlag in der Vorrede zum Mainzer Konzil von 847, die feststellt, dass die Kirchen entgegen den Bedrängungen der Zeit ihre Ehre haben sollten und durch ihre Immunität ihre Besitzungen vor Übergriffen geschützt sein sollten. ${ }^{69}$ Die Immunität tritt folglich als Raum neben die anders geartete Vorstellung des direkten Schutzes der Kirchengebäude vor gewalttätigen Übergriffen. Die Verfestigung der Idee schlägt sich dann auch in einem Kapitular Karls des Kahlen nieder, das den Immunitätsbruch bei gleichzeitiger Exkommunikation mit einer 60 solidi Bannbuße belegt, die sich bei Ungehorsam in eine Todesstrafe wandelt. Auffällig ist hier, dass zur räumlichen Beschreibung von den clausta ęcclesiarum im Bezug auf die Immunität die Rede ist, damit wird ein geschlossener Raum evoziert, der aber über das Kirchengebäude hinaus geht. ${ }^{70}$

Es zeigt sich also, dass Konzepte, die sich in erster Linie mit der Immunität beschäftigen, zu kurz greifen, da sie die Modelle, die Heinrich Brunner unter dem Begriff des Sonderfriedens ge- fasst hat, nicht berücksichtigen. Dennoch ergeben sich auch aus Brunners Deutung Probleme. So sind nur die wenigsten der hier vorgestellten Vergehen von den Quellen ausdrücklich als Friedensverletzung gekennzeichnet. Vielmehr verwenden die Quellen häufiger den Begriff publicus und vermitteln damit den Eindruck, die Gesetzgebung habe in erster Linie das Interesse, essentielle die Gesellschaft bedrohende Vergehen zu unterdrücken. In diesem Sinne kann der Sonderfrieden Brunner folgend nicht mehr als ein Ausdruck eines wie auch immer gearteten Tabus, das letztlich die Sakralsphäre des Königs betrifft, charakterisiert werden, sondern muss als Teil eines komplexen und umfassenden Versuchs der Einschränkung der Selbsthilfe verstanden werden. Daneben lässt sich in Bezug auf die Kirche auch noch der Begriff des honor fassen, der eine räumliche Dimension hat und sich auf das Motiv der Gottesfurcht zurückführen lässt, aber durch den Gesetzgeber garantiert wird. Inwieweit sich eine besondere Friedensvorstellung aus den Bußen, die in den süddeutschen leges noch als fredus bezeichnet werden und in den Kapitularien als bannus auftauchen, ablesen lässt, ist in Bezug auf das Gewaltmonopol des Königs hier nicht auszudeuten. Dafür bräuchte es eine genauere Untersuchung der Systematik der Bußen, des Bannes sowie der individuellen urkundlichen Schutzbestimmungen, die unter der vorliegenden Fragestellung nicht zu leisten war.

Letztlich ist auch die dem Modell Brunners zugrunde liegende Vorstellung, die Heraushebung bestimmter Räume entspräche einem grundsätzlichen Rechtszustand, zu modifizieren. Jene stellt eine Rechtsentwicklung dar, die in den leges allerdings keine vollkommene systematische Übereinstimmung der mit den Räumen verknüpften Vorstellungen erreichte, sondern im zugrundeliegen-
67 Die Relevanz dieses Rechtssatzes wird dadurch unterstrichen, dass es eine spätere Rezeption erfährt, siehe: Das Sendhandbuch des Regino von Prüm, II c. 31 (Hartmann 2004a, $264 \mathrm{f}$.).

68 Rosenwein (1999) bes. 7-8.

69 Konzil von Mainz 847, in: HartmanN (1984) 161: Sed pro dolor! Istis temporibus nec loca sancta venerantur neque ministri dei condigne honorantur, sed versa vice illi, qui honorari debuerant, flagellantur, spoliantur atque diversis calumniis fatigantur. Unde necessitas magna nos coegit pro hac re ad vos reclamare et petere, ut, sicut apud antecessores vestros reges atque imperatores, qui ante vos fuerunt, honorem sancta dei ecclesia habuit et per immunitatem eorum possessiones aecclesiasticae inconvulsae persititerunt manentesque in eis semper inlesi perserveraverunt; ita apud vos modernis temporibus incominatae permaeant.

70 Caroli (Calvi?) Capitulum de immunitate infrecta (a. 840/877?) in: MordeK (1995) 1020. 
den Denkrahmen unterschiedliche Ausprägungen erfuhr. Das ist besonders in Bezug auf die Kirche als Asylort festzustellen. Schließlich verweisen die unterschiedlichen Regelungen alle auf die Vorstellung, dass die Kirchen eben nicht nur Kultzentren waren, sondern durch die Öffentlichkeit geschützte gewaltfreie Räume sein sollten, die im Rechtssystem eine eigene Stellung einnahmen. Aus der
Perspektive der Frage nach Zentralität und Peripherie macht dieses Beispiel deutlich, dass der Gegensatz in gewisser Weise völlig aufgelöst wird, denn hier sollen selbst in der Peripherie zentrale Orte geschaffen werden.

\section{Bibliographie}

- Bachrach, David (2013), Immunities as tools of royal military policy under the Carolingians and Ottonian kings, in: Zeitschrift der Savigny-Stiftung für Rechtsgeschichte. Germanistische Abteilung 130, 1-36

- Becher, Matthias (2013), Gewaltmission. Karl der Große und die Sachsen, in: Credo. Christianisierung Europas im Mittelalter, Bd. I: Essays, hg. v. Christoph Stiegemann u. a., Petersberg, 321-329

- Beyerle, Franz, Rudolf Buchner (Hg.) (1954), Lex Ribuaria, (MGH LL nat. Germ. III 2), Hannover

- Beyerle, Fritz (1928), Die Lex Ribuaria, in: Zeitschrift der Savigny-Stiftung für Rechtsgeschichte. Germanistische Abteilung $48,264-378$

- Beyerle, Fritz (1935), Das Gesetzbuch Ribuariens, in: Zeitschrift der Savigny-Stiftung für Rechtsgeschichte. Germanistische Abteilung 55, 1-80

- Beyerle, Konrad (Hg.) (1926), Lex Baiuvariorum. Lichtdruckwiedergabe der Ingolstädter Handschrift des bayrischen Volksrechts mit Transkription, Textnoten, Übersetzung, Einführung, Literaturübersicht und Glossar, München

- Boretius, Alfred E. (Hg.) (1883), Capitularia regum Francorum I, (MGH Capit. I), Hannover

- Brühl, Carlrichard (1995), Die merowingische Immunität, in: Chiesa e mondo feudale nei secoli X-XII. Atti della dodicesima Settimana internazionale di studio, Mendola, 24-28 agosto 1992, Milano, 28-44

- Brunner, Heinrich (1928), Deutsche Rechtsgeschichte, neu bearb. v. Claudius Freiherr von Schwerin, 2. Aufl. Berlin, ND 1958

- Buchner, Rudolf (1952), Kleine Untersuchungen zu den fränkischen Stammesrechten, in: Deutsches Archiv für Erforschung des Mittelalters 9, 79-101

- Clerce, Charles de (Hg.) (1963), Concilia Galliae A. 511-A. 695, (CCL 48A), Turnhout

- Czock, Miriam (2012), Gottes Haus. Untersuchungen zur Kirche als heiligem Raum von der Spätantike bis ins Frühmittelalter, Berlin

- Dilcher, Gerhard (1996), Friede durch Recht, in: Träger und Instrumentarien des Friedens im hohen und späten Mittelalter, hg. v. Fried, Johannes, Sigmaringen, 203-227

- Dilcher, Gerhard, Eva-Maria Distler (Hg.) (2006), Leges - Gentes - Regna: Zur Rolle von germanischen Rechtsgewohnheiten und lateinischer Schriftradition bei der Ausbildung der frühmittelalterlichen Rechtskultur, Berlin

- Dreier, Horst, Fabian Wittreck (2009), Rechtswissenschaft, in: Raumwissenschaften, hg. v. GünZel, Stephan, Frankfurt a. M., 338-353

- Eckhardt, Karl August (Hg.) (1959), Lex Ribuaria: 1: Austrasisches Recht im 7. Jahrhundert, (Germanenrechte, N. F. 6/1), Göttingen, 7-144

- Eckhardt, Karl August (Hg.) (1962), Pactus legis Salicae, (MGH LL nat. Germ. IV 1), Hannover

- Eckhardt, Karl August (Hg.) (1966), Lex Ribuaria: 2: Text und Lex Francorum Chamavorum, (Germanenrechte, N. F. 6/2), Hannover

- Eckhardt, Karl August (Hg.) (1966), Lex Alamannorum, (MGH LL nat. Germ. 5,1), Hannover

- Eckhardt, Karl August, Albrecht Eckhardt (Hg.) (1982), Lex Frisionum, (MGH Fontes iuris XII), Hannover

- Epp, Verena (1998), Zur Kategorie des Raumes in frühmittelalterlichen Rechtstexten, in: Raum und Raumvorstellungen im Mittelalter, hg. v. Aertsen, Jan A., Andreas Speer, Berlin, 575-590

- Esders, Stefan (1993), Rechtsdenken und Traditionsbewusstsein in der gallischen Kirche zwischen Spätantike und Frühmittelalter. Zur Anwendbarkeit soziologischer Rechtsbegriffe am Beispiel des kirchlichen Asylrechts im 6. Jahrhundert, in: Francia 20, 97-125

- Esders, Stefan (2007), Eliten und Raum nach Frühmittelalterlichen Rechtstexten. Überlegungen zu einem Spannungsverhältnis, in: Les élites et leurs espaces. Mobilité, rayonnement, domination (du VI ${ }^{\mathrm{e}}$ au XI ${ }^{\mathrm{e}}$ siècle), hg. v. Depreux, Philippe u. a., Turnhout, $11-28$

- Esders, Stefan (2009), Rechtliche Grundlagen frühmittelalterlicher Staatlichkeit: der allgemeine Treueid, in: Der frühmittelalterliche Staat - Europäische Perspektiven, hg. v. Pohl, Walter, Veronika Wieser, Wien, 423-432

- Ewig, Eugen (1976), Die Stellung Ribuariens in der Verfassungsgeschichte des Merowingerreiches, in: Spätantikes und fränkisches Gallien. Gesammelte Schriften Bd. 1, Zürich, 450-503

- Fastrich-Sutty, Isabella (2000), Die Rezeption des westgotischen Rechts in der Lex Baiuvariorum, Köln 
- Franke, Gerhard (2003), Das Kirchenasyl im Kontext sakraler Zufluchtnahmen in der Antike. Historische Zufluchtnahmen und theologische Implikationen in patristischer Zeit, Frankfurt a. M.

- Fruscione, Daniela (2003), Das Asyl bei den germanischen Stämmen im frühen Mittelalter, Köln

- Georges, Karl Ernst (1972), Art. »Honor«, in: Ausführliches lateinisch-deutsches Handwörterbuch, Bd. I, Hannover, Sp. 3073-3074

- Gergen, Thomas (2004), Pratique juridique de la paix et trêve de Dieu à partir du concile de Charroux (989-1250). Juristische Praxis der Pax und Treuga Dei ausgehend vom Konzil von Charroux (989-1250), Frankfurt a. M.

- Goebel, Julius (1937), Felony and misdemeanor. A study in the history of criminal law, New York

- Goetz, Hans-Werner (2002), Die Gottesfriedensbewegung im Licht neuerer Forschungen, in: Landfrieden. Anspruch und Wirklichkeit, hg. v. Buschmann, Arno, Elmar Wadle, Paderborn, 31-54

- Hartmann, Wilfried (Hg.) (1984), Die Konzilien der karolingischen Teilreiche 843-859, (MGH Conc. III), Hannover

- Hartmann, Wilfried (1992), Der Friede im früheren Mittelalter. Zwei Studien, Barbüttel

- Hartmann, Wilfried (Hg.) (2004a), Das Sendhandbuch des Regino von Prüm, Darmstadt

- Hartmann, Wilfried (2004b), Einige Fragen zur Lex Alamannorum, in: Der Südwesten im 8. Jahrhundert aus historischer und archäologischer Sicht, hg. v. Nuber, Hans Ulrich u. a., Sigmaringen, 313-333

- Head, Thomas, Richard Landes (1992), The peace of God. Social violence and religious response in France around the year 1000 , Ithaca

- Heidrich, Ingrid (1973), Die Verbindung von Schutz und Immunität. Beobachtungen zu den merowingischen und frühkarolingischen Schutzurkunden für St. Calais, in: Zeitschrift der Savigny-Stiftung für Rechtsgeschichte. Germanistische Abteilung 90, 10-39

- Hen, Yitzhak (2006), Charlemagne's Jihad, in: Viator 37, 33-52

- Hermann, Hans-Georg (2008), Art. Frieden, in: Handwörterbuch zur deutschen Rechtsgeschichte, 2. Aufl., Sp. 1807-1821

- Hoffmann, Hartmut (1964), Gottesfrieden und Treuga Dei, Stuttgart

- Holzner, Thomas (2010), Die Decreta Tassilonis. Regelungsgehalt, Verhältnis zur Lex Baiuvariorum und politische Implikationen, Berlin

- Jellinek, Georg (1922), Allgemeine Staatslehre, 3. Aufl., Berlin

- Kampmann, Christoph (2006), Art. Frieden, in: Enzyklopädie der Neuzeit, Bd. 4, Stuttgart, Sp. 1-21

- Kannowski, Bernd (2002), Rechtsbegriffe im Mittelalter: Stand der Diskussion, in: Rechtsbegriffe im Mittelalter, hg.v. Cordes, Albrecht, Frankfurt a. M., 1-27

- Kölzer, Theo (2005), Ludwig der Fromme (814-840) im Spiegel seiner Urkunden, Paderborn

- Kottje, Raymund (1986), Die Lex Baiuvariorum - das Recht der Baiern, in: Überlieferung und Geltung normativer Texte des frühen und hohen Mittelalters, hg. v. Mordek, Hubert, Sigmaringen, 9-23

- Lambert, Thomas B. (2009a), Protection, feud and royal power. Violence and its regulation in English law c. 850 - c. 1250 , Diss. masch. Durham

- Lambert, Thomas B. (2009b), Spiritual protection and secular power: The evolution of sanctuary and legal privilege in Ripon and Beverley, 900-1300, in: Peace and protection in the Middle Ages, hg. v. Lambert, Thomas B., David Rollason, Toronto, 121-140

- Landau, Peter (2004), Die Lex Baiuvariorum. Entstehungszeit, Entstehungsort und Charakter von Bayerns ältester Rechts- und Geschichtsquelle, München

- Magnou-Nortier, Elisabeth (1981), Études sur le privilège d'immunité du IV au IX ${ }^{\mathrm{e}}$ siècle, in: Revue Mabillon 69, 465-512

- Magnou-Nortier, Elisabeth (1992), The enemies of peace: reflections on a vocabulary, 500-1100, in: The peace of God. Social violence and religious response in France around the year 1000, Ithaca, 58-79

- Maurer, Hartmut (2010), Staatsrecht I. Grundlagen, Verfassungsorgane, Staatsfunktionen, 6. Aufl., München

- Merkel, Johannes (Hg.) (1863), Lex Alamannorum, (MGH LL 3), Hannover

- Mordek, Hubert (Hg.) (1995), Bibliotheca capitularium regum Francorum manuscripta. Überlieferung und Traditionszusammenhang der fränkischen Herrschererlasse, München

- Mordek, Hubert u. a. (Hg.) (2012), Die Admonitio generalis Karls des Großen, (MGH Fontes juris XVI), Hannover

- Murray, Alexander C. (1994), Immunity, nobility and the Edict of Paris, in: Speculum 69, 18-39

- Nehlsen, Hermann (1978), Der Grabfrevel in den germanischen Rechtsaufzeichnungen, in: Zum Grabfrevel in vor- und frühgeschichtlicher Zeit. Untersuchungen zu Grabraub und »haugbrot« in Mittel- und Nordeuropa, hg. v. JaHnkuHN, HerberT u. a., Göttingen, 107-168

- Nehlsen, Hermann (2008), Reaktionsformen der Gesellschaft auf Verletzung und Gefährdung von Gemeinschaftsinteressen in Spätantike und frühem Mittelalter bei den germanischen Stämmen. Ein Beitrag zur Strafrechtsgeschichte, in: Das Recht und seine historischen Grundlagen. Festschrift für Elmar Wadle zum 70. Geburtstag, hg. v. Chiusi, Tiziana J. u. a., Berlin, 759-781

- Niermeyer, Jan Frederik (2002), Art. »Honor«, in: Niermeyer, Jan Frederik, Co van de Kieft, Mediae Latinitatis Lexicon minus, 2. Aufl., Darmstadt, 647-651

- Patzold, Steffen (2005), Die Veränderungen frühmittelalterlichen Rechts im Spiegel der >Leges«-Reformen Karls des Großen und Ludwigs des Frommen, in: Rechtsveränderungen im politischen und sozialen Kontext mittelalterlicher Rechtsvielfalt, hg. v. Esders, Stefan, Christine Reinle, Münster, 63-99

- Renard, Étienne (2009), Le »Pactus Legis Salicae«, règlement militaire romain ou code de loi compilé sous Clovis?, in: Bibliothèque de l'École des chartes 167, 321-352

- Rosenwein, Barabara (1999), Negotiating space. Power, restraint, and privileges of immunity in early medieval Europe, Manchester

- Rǘckert, JoAchim (2006), Rechtsbegriff oder Rechtsbegriffe - germanisch, römisch, kirchlich, heutig?, in: DilcheR/ DistLeR (Hg.) (2006) 569-602 
- Schott, Clausdieter (1974), Pactus, Lex und Recht, in: Die Alemannen in der Frühzeit, hg. v. Hübener, Wolfgang, Bühl, $135-168$

- Schott, Clausdieter (Hg.) (1997), Lex Alamannorum - Gesetz und Verfassung der Alemannen, Augsburg

- Schott, Clausdieter (2006), Lex und Skriptorium - Eine Studie zu den süddeutschen Stammesrechten, in: Dilcher / Distler (Hg.) (2006) 257-290

- Schubert, Ernst (1993), Die Capitulatio de partibus Saxoniae, in: Geschichte der Region. Zum 65. Geburtstag von Heinrich Schmidt, hg. v. Brosius, Dieter u. a. Hannover, 3-28

- Schumann, Eva (2006), Entstehung und Fortwirkung der Lex Baiuvariorum, in: Dilcher/Distler (Hg.) (2006) 291-319

- Schwerin, Claudius Freiherr von (Hg.) (1918), Leges Saxonum und Lex Thuringorum, (MGH Fontes iuris IV), Hannover/ Leipzig

- Schwind, ERnst von (Hg.) (1926), Leges Baiwariorum, (MGH LL nat. Germ. V 2), Hannover

- Semmler, Josef (1959), Traditio und Königsschutz. Studien zur Geschichte der königlichen Monasteria, in: Zeitschrift der Savigny-Stiftung für Rechtsgeschichte. Kanonistische Abteilung 45, 1-33

- Siems, Harald (1980), Studien zur Lex Frisionum, Ebelsbach

- Siems, Harald (2006), Das Lebensbild der Lex Baiuvariorum, in: Rechtssetzung und Rechtswirklichkeit in der bayerischen Geschichte, hg. v. Hecker, Hans-Joachim u. a., München, 29-73

- Springer, Matthias (2009), Fragen um das altsächsische Recht, in: Grundlagen für ein neues Europa. Das Magdeburger und Lübecker Recht in Spätmittelalter und Früher Neuzeit, hg. v. LücK, HeINER u. a., Köln, 283-304

- Störmer, Wilhelm (1990), Zum Prozeß sozialer Differenzierung bei den Bayern von der Lex Baiuvariorum bis zur Synode von Dingolfing, in: Typen der Ethnogenese unter besonderer Berücksichtigung der Bayern, hg. v. Wolfram, Herwig, Walter PoнL, Bd. I, Wien, 155-170

- Ubl, Karl (2009), L'origine contestée de la loi salique. Une mise au point, in: Revue de l'Institut français d'histoire en Allemagne 1, 208-234

- Wadle, Elmar (1996), Gottesfrieden und Landfrieden als Gegenstand der Forschung nach 1950, in: Funktion und Form. Quellen- und Methodenprobleme der mittelalterlichen Rechtsgeschichte, Berlin, 63-91

- Wadle, Elmar (2006), Frieden, Zwang, Recht - Ein Versuch, Zusammenhänge in der Zeit der leges zu deuten, in: Dilcher/ Distler (Hg.) (2006) 549-560

- WinkLer, GüNther (1999), Raum und Recht, Wien, New York

- Woll, INGRID (1995), Untersuchungen zu Überlieferung und Eigenart der merowingischen Kapitularien, Frankfurt a. M. 